\title{
Chapter 13 \\ Indoor Deposition of Radiocaesium in an Evacuation Area in Odaka District of Minami-Soma After the Fukushima Nuclear Accident
}

\author{
Hiroko Yoshida-Ohuchi, Takashi Kanagami, Yasushi Satoh, \\ Masahiro Hosoda, Yutaka Naitoh, and Mizuki Kameyama
}

\begin{abstract}
The indoor deposition of radiocaesium was investigated for 27 wooden houses in eight areas of Kanaya, Mimigai, Ootawa, Ooi, Kamiyama, Kamiura, Ebizawa, and Yoshina in Odaka district of Minami-Soma, Fukushima Prefecture from November 2013 to January 2015. Odaka district is within a $20 \mathrm{~km}$ radius of the Fukushima Daiichi nuclear power plant (FDNPP), which used to be designated as a restricted area and has been designated as an evacuation area. Dry smear test was performed over an area of $100 \mathrm{~cm}^{2}$ on the surface of materials made of wood, glass, metal, and plastic in the rooms and the surface of wooden structure in the roof-space. Approximately 1000 smear samples were collected in total; $89 \%$ of the smear samples obtained in the rooms exceeded the detection limit $\left(0.004 \mathrm{~Bq} / \mathrm{cm}^{2}\right)$ and a maximum value was evaluated to be $1.54 \mathrm{~Bq} / \mathrm{cm}^{2} ; 77 \%$ of the smear samples taken from the wooden structure in the roof-space exceeded the detection limit and a maximum value was evaluated to be $1.14 \mathrm{~Bq} / \mathrm{cm}^{2}$. Area differences in surface contamination were observed. Assuming that two horizontal phases of the room have uniform surface contamination with the maximum median
\end{abstract}

\footnotetext{
H. Yoshida-Ohuchi $(\varangle) \bullet$ T. Kanagami

Tohoku University, Sendai, Miyagi, Japan

e-mail: hiroko@m.tohoku.ac.jp; four020@gmail.com

Y. Satoh

Advanced Industrial Science and Technology, Tsukuba, Ibaraki, Japan

e-mail: yss.sato@aist.go.jp

M. Hosoda

Hirosaki University, Hirosaki, Aomori, Japan

e-mail:m_hosoda@cc.hirosaki-u.ac.jp

Y. Naitoh • M. Kameyama

Japan Environment Research Co., Ltd., Sendai, Miyagi, Japan

e-mail: yutaka-naitou@jer.co.jp; mizuki-kameyama@jer.co.jp 
radioactivity observed in Kamiura $\left(0.1 \mathrm{~Bq} / \mathrm{cm}^{2}\right)$ for 27 houses investigated, the ambient dose equivalent rate for ${ }^{134} \mathrm{Cs}$ and ${ }^{137} \mathrm{Cs}$ in November 2013 was calculated as approximately $0.002 \mu \mathrm{Sv} / \mathrm{h}$.

Keywords Odaka district of Minami-Soma $•$ Evacuation area - Wooden houses

- Indoor surface contamination • Fukushima nuclear accident $\bullet$ Smear method

\subsection{Introduction}

The Great East Japan Earthquake of magnitude 9.0 and the tsunami on March 11, 2011 resulted in major damage to the Fukushima Daiichi nuclear power plant (FDNPP). From March 12 onward, various incidents at multiple units occurred including hydrogen explosions, smoke, and a fire [1] and a large amount of radioactive material was released into the environment and moved as a radioactive plume with the wind [1,2]. In the evening on March 12, a reading of $20 \mu \mathrm{Sv} / \mathrm{h}$ was observed from a measurement made at the joint government building of the city of Minami-Soma, and it is believed that the plume was first blown south by a weak northerly wind and then diffused to the north by a strong southerly wind [1]. In the absence of precipitation, the dispersed pollution caused dry deposition during the radioactive plume pass through the area. In particular, low airtightness in Japanese wooden houses can be the cause of indoor dry deposition [3]. Dry deposition is important as well as wet deposition when assessing the consequences of nuclear accident in the context of risk assessment, as dry deposition is close to where residents live and doses from deposited long-lived contaminants are usually the major long-term hazards. It is necessary for residents to know the level of indoor deposition when they plan temporary access or return home. In this study, the indoor deposition of radiocaesium was investigated for 27 wooden houses in eight areas in Odaka district of Minami-Soma. Then, we assessed the influence of surface contamination on the ambient dose equivalents.

\subsection{Methods}

\subsubsection{Locations of Houses Investigated}

From November 2013 to January 2015, the indoor deposition of radiocaesium was investigated for 27 wooden houses in eight areas of Kanaya, Mimigai, Ootawa, Ooi, Kamiyama, Kamiura, Ebizawa, and Yoshina in Odaka district of MinamiSoma, Fukushima Prefecture, as shown in Fig. 13.1. Odaka district, located on the southern end of Minami-Soma, is within a $20 \mathrm{~km}$ radius of the FDNPP and all residents were evacuated immediately after the evacuation instruction was issued on March 12, 2011 [1]. On April 22, 2011, Odaka district was shifted to legally 

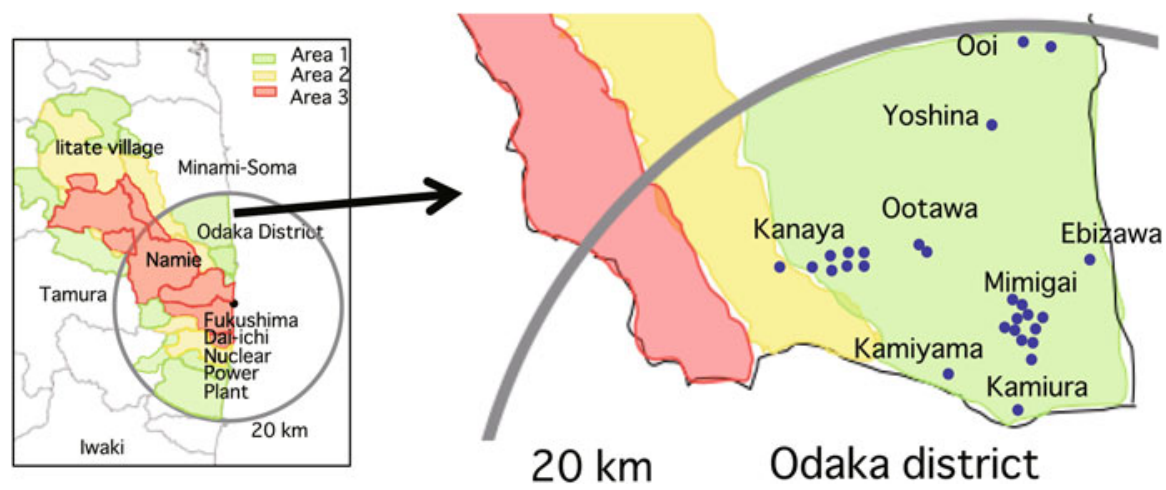

Odaka district

Fig. 13.1 Current status of Odaka district of Minami-Soma, Fukushima Prefecture in April 2015 and the locations of the houses. One blue, closed circle corresponds to one house at each location

enforceable restricted area [1]. On April 16, 2012, the restricted area was rearranged into three areas responding to the annual cumulative dose [1]. Areas 1, 2, and 3 are those in which the evacuation orders were ready to be lifted; in which the residents are not permitted to live; and where it is expected that the residents will have difficulty returning for a long time, respectively [4]. The Odaka residents were prohibited any access to their homes until April 2012. Decontamination work started from 2014 in Odaka district during the investigation of this study. It did not affect the investigation as it was conducted for the yard, the roof, and the gutter but not for the interior of the house. The current status of Odaka district on April 2015 and the locations of the houses investigated are shown in Fig. 13.1. One blue, closed circle corresponds to one house at each location. All houses are made of wood and are one- and/or two-story structures.

\subsubsection{Measurement of Surface Contamination}

To estimate surface contamination, dry smear test was performed on the surface of materials in the rooms and in the roof-space. The surfaces over an area of $100 \mathrm{~cm}^{2}$ of materials were rubbed with moderate pressure using a round smear test paper with a diameter of $2.5 \mathrm{~cm}$. The smear samples were carefully collected from the flat places that were not cleaned or wiped by residents, in every room, and 991 samples were collected in total. The numbers of houses and collected samples for surfaces of wooden, metal, glass, and plastic materials in the rooms, of wooden structure in the roof-space, and of wooden column in the rooms for each area are summarized in Table 13.1.

Radioactivity on smear test paper was measured for 5 min with a plastic scintillator detector JSD-5300 (Hitachi Aloka Medical, Ltd., Japan) and/or a liquid scintillation counter LS-6500 (Beckman Coulter, Inc.) using beta rays emitted from ${ }^{134} \mathrm{Cs}$ and ${ }^{137} \mathrm{Cs}$, which are dominant nuclides in the investigated period. 
Table 13.1 The numbers of houses and collected samples for surfaces of wooden, metal, glass, and plastic materials in the rooms, of wooden structure in the roof-space, and of wooden column in the rooms for each area and the numbers of smear samples exceeded the detection limit $\left(0.004 \mathrm{~Bq} / \mathrm{cm}^{2}\right)$ and below the detection limit for each area

\begin{tabular}{|c|c|c|c|c|c|c|c|c|c|c|}
\hline & \multirow[b]{2}{*}{$\begin{array}{l}\text { Numbers } \\
\text { of } \\
\text { houses }\end{array}$} & \multicolumn{3}{|c|}{$\begin{array}{l}\text { Wooden, metal, glass, } \\
\text { and plastic materials } \\
\text { in the rooms }\end{array}$} & \multicolumn{3}{|c|}{$\begin{array}{l}\text { Wooden structure in the } \\
\text { roof-space }\end{array}$} & \multicolumn{3}{|c|}{$\begin{array}{l}\text { Wooden column in } \\
\text { the rooms }\end{array}$} \\
\hline & & $\begin{array}{l}\text { Numbers } \\
\text { of } \\
\text { samples }\end{array}$ & $<\mathrm{ND}$ & $>\mathrm{ND}$ & $\begin{array}{l}\text { Numbers } \\
\text { of } \\
\text { samples }\end{array}$ & $<\mathrm{ND}$ & $>\mathrm{ND}$ & $\begin{array}{l}\text { Numbers } \\
\text { of } \\
\text { samples }\end{array}$ & $<\mathrm{ND}$ & $>\mathrm{ND}$ \\
\hline Kamiura & 1 & 31 & 2 & 29 & 2 & 0 & 2 & 2 & 2 & 0 \\
\hline Kamiyama & 1 & 46 & 0 & 46 & 5 & 0 & 5 & 4 & 2 & 2 \\
\hline Kanaya & 8 & 231 & 11 & 220 & 45 & 4 & 41 & 16 & 16 & 0 \\
\hline Ootawa & 2 & 43 & 1 & 42 & 7 & 2 & 5 & 4 & 4 & 0 \\
\hline Yoshina & 1 & 36 & 0 & 36 & 5 & 0 & 5 & 2 & 2 & 0 \\
\hline Ebizawa & 1 & 29 & 4 & 25 & 1 & 0 & 1 & 2 & 1 & 1 \\
\hline Mimigai & 11 & 334 & 47 & 287 & 52 & 22 & 30 & 18 & 14 & 4 \\
\hline Ooi & 2 & 65 & 21 & 44 & 7 & 1 & 6 & 4 & 4 & 0 \\
\hline Total & 27 & 815 & 86 & 729 & 124 & 29 & 95 & 52 & 45 & 7 \\
\hline
\end{tabular}

In order to estimate the total removable surface contamination, radioactivity on smear test paper $\left(\mathrm{Bq} / \mathrm{cm}^{2}\right)$ was obtained by the following equation $[5,6]$ :

$$
\mathrm{A}_{\mathrm{sr}}=\frac{\mathrm{n}-\mathrm{n}_{\mathrm{b}}}{60 \cdot \varepsilon_{\mathrm{i}} \cdot \mathrm{F} \cdot \mathrm{S} \cdot \varepsilon_{\mathrm{s}}}
$$

where $\mathrm{n}$ is the gross count rate $\left(\mathrm{min}^{-1}\right), \mathrm{n}_{\mathrm{b}}$ is the background count rate $\left(\mathrm{min}^{-1}\right), \varepsilon_{\mathrm{i}}$ is the instrument efficiency, $\mathrm{F}$ is the removal fraction, $\mathrm{S}$ is the surface area covered by the smear, for example, $100 \mathrm{~cm}^{2}$, and $\varepsilon_{\mathrm{s}}$ is the source efficiency, that is, the fraction of the decays within the sample that results in a particle of radiation leaving the surface of the source.

The combined efficiency of the instrument and the source for each detector of the plastic scintillator detector and the liquid scintillation counter was determined by measuring a part of samples simultaneously using a high-purity germanium (HPGe) detector ORTEC-GMX-20195-S (AMETEK Inc., USA). The removal fraction was determined by the use of repetitive wipes $[5,6]$ and the average $\pm \sigma$ of the values was evaluated to be $0.65 \pm 0.28$. All values of radioactivity were corrected to those in November 2013.

The detection limit, $N_{d}$, was defined as 3 standard deviation and calculated by the following equation [7]:

$$
\mathrm{N}_{\mathrm{d}}=\frac{3}{2}\left[\frac{3}{\mathrm{~T}_{\mathrm{s}}}+\sqrt{\left(\frac{3}{\mathrm{~T}_{\mathrm{s}}}\right)^{2}+4 \mathrm{~N}_{\mathrm{b}}\left(\frac{1}{\mathrm{~T}_{\mathrm{s}}}+\frac{1}{\mathrm{~T}_{\mathrm{b}}}\right)}\right]
$$


where $N_{d}$ is the background count rate $\left(\mathrm{min}^{-1}\right), T_{s}$ and $T_{b}$ are the counting time of the sample and the background ( $\mathrm{min}$ ), respectively, for example, $5 \mathrm{~min}$.

The lower detection limit for surface contamination was obtained when the smear samples were measured using the liquid scintillation counter. The detection limit was evaluated to be $0.004 \mathrm{~Bq} / \mathrm{cm}^{2}$ with Eqs. (13.1) and (13.2).

\subsection{Results and Discussion}

\subsubsection{Indoor Surface Contamination for Odaka Houses}

The numbers of smear samples, which were collected from surfaces of wooden, metal, glass, and plastic materials in the rooms, of wooden structure in the roofspace, and of wooden column in the rooms for each area, that exceeded the detection limit and below the detection limit in each area are summarized in Table 13.1. Eighty-nine percent (729/815) of the smear samples obtained in the rooms exceeded the detection limit and a maximum value was evaluated to be $1.54 \mathrm{~Bq} / \mathrm{cm}^{2}$. Seventyseven percent (95/124) of the smear samples taken from wooden structure in the roof-space exceeded the detection limit and a maximum value was evaluated to be $1.14 \mathrm{~Bq} / \mathrm{cm}^{2}$. This result indicates that the pollution deposited not only in the interior of the house but also in the structure in the roof-space. However, only $13.5 \%$ (7/52) of the smear samples exceeded the detection limit for wooden column in the rooms with a maximum value of $0.07 \mathrm{~Bq} / \mathrm{cm}^{2}$. This difference between former two results and the latter one indicates that radiocaesium deposition on a vertical surface is considerably lower than that on a horizontal surface. The median surface contamination with an interquartile range evaluated from surfaces of wooden, metal, glass, and plastic materials in the rooms for 27 houses in each area is shown in Fig. 13.2a. The interquartile range is expressed by Q1-Q3, which are the middle values in the first half and the second half of the rank-ordered data set, respectively. There seems to be a difference in the median surface contamination depending on areas. In the same manner, the median surface contamination with an interquartile range evaluated from surfaces of wooden structure in the roof-space for houses in each area is shown in Fig. 13.2b. The order of indoor surface contamination was the same between in the rooms and in the roof-space except a value for the house in Yoshina, as shown in Figs. 13.2a, b. Three areas of Ebizawa, Mimigai, and Ooi showing smaller values of the median surface contamination with an interquartile range in Fig. 13.2a, b are located closer to the ocean.

The houses of Kanaya and Mimigai showing a difference in the median surface contamination with an interquartile range in Fig. 13.2a, b are compared. The values of surface contamination in each house Kanaya and Mimigai, in which 8 and 11 houses were investigated, respectively, are shown in Fig. 13.3. The value of median surface contamination with an interquartile range for each house in two areas is exhibited in the left group and the right group, respectively. Generally, it was observed that the values of surface contamination in Kanaya tended to be 

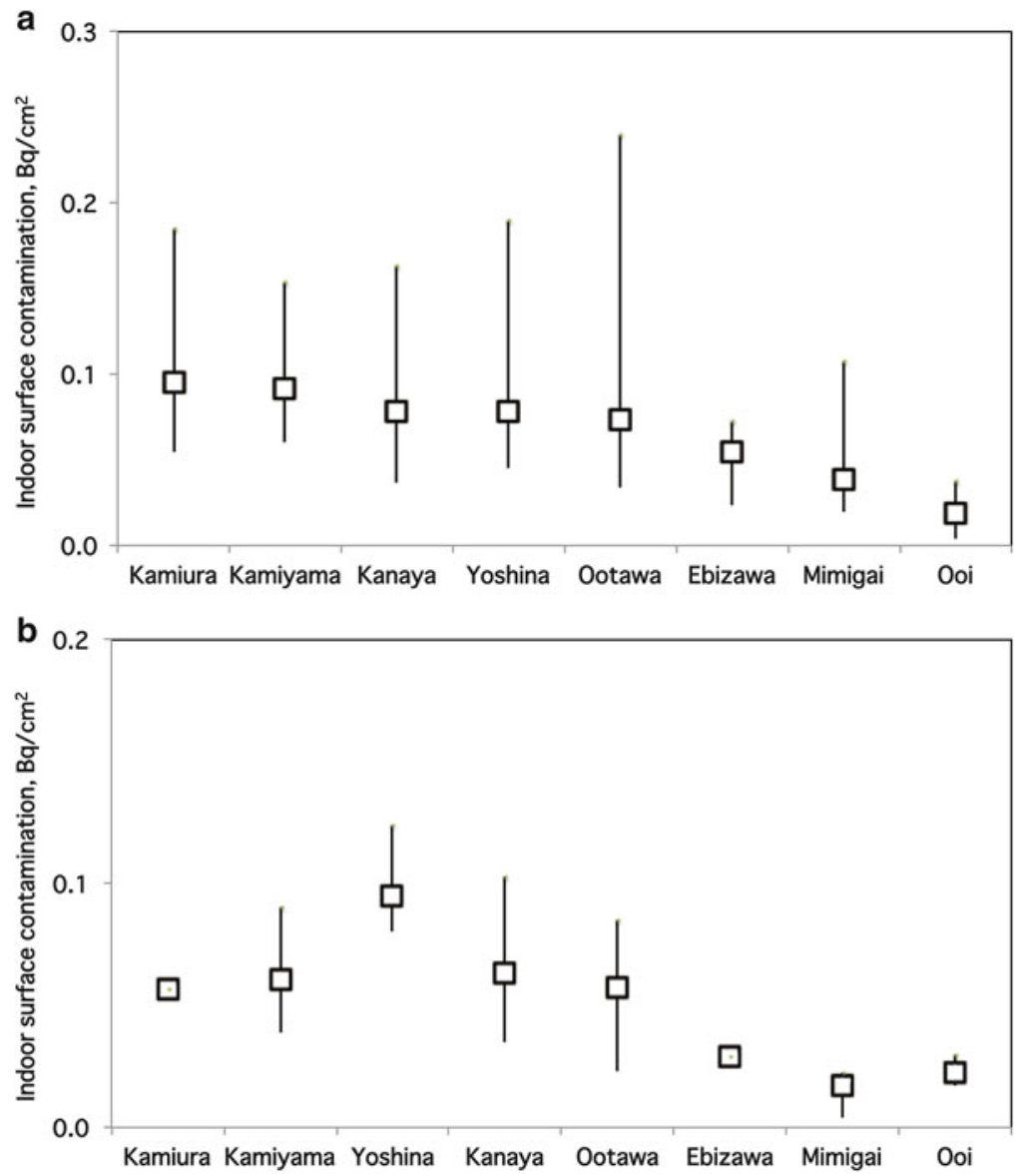

Fig. 13.2 (a) Median surface contamination with an interquartile range evaluated from surfaces of wooden, metal, glass, and plastic materials in the rooms for 27 houses in each area. The median and the interquartile range Q1-Q3 are expressed as squares and the bar, respectively. (b) Median surface contamination with an interquartile range evaluated from surfaces of wooden structure in the roof-space for houses in each area. The median and the interquartile range Q1-Q3 are expressed as squares and the bar, respectively

larger than those in Mimigai; however, a large discrepancy for each individual house was observed in both groups. The difference in characteristics of the houses, which showed the maximum and the minimum median surface contamination, in each group between Kanaya-A and Kanaya-B and between Mimigai-I and Mimigai-S was considered. There was no relationship between the value of surface contamination and the size of the house, the age of the building, the direction of the building (each entrance faces the south or the southeast direction), or area topography around the house. There is no difference in distance from the FDNPP among houses in each group, either. It was noted that residents of both, the houses 


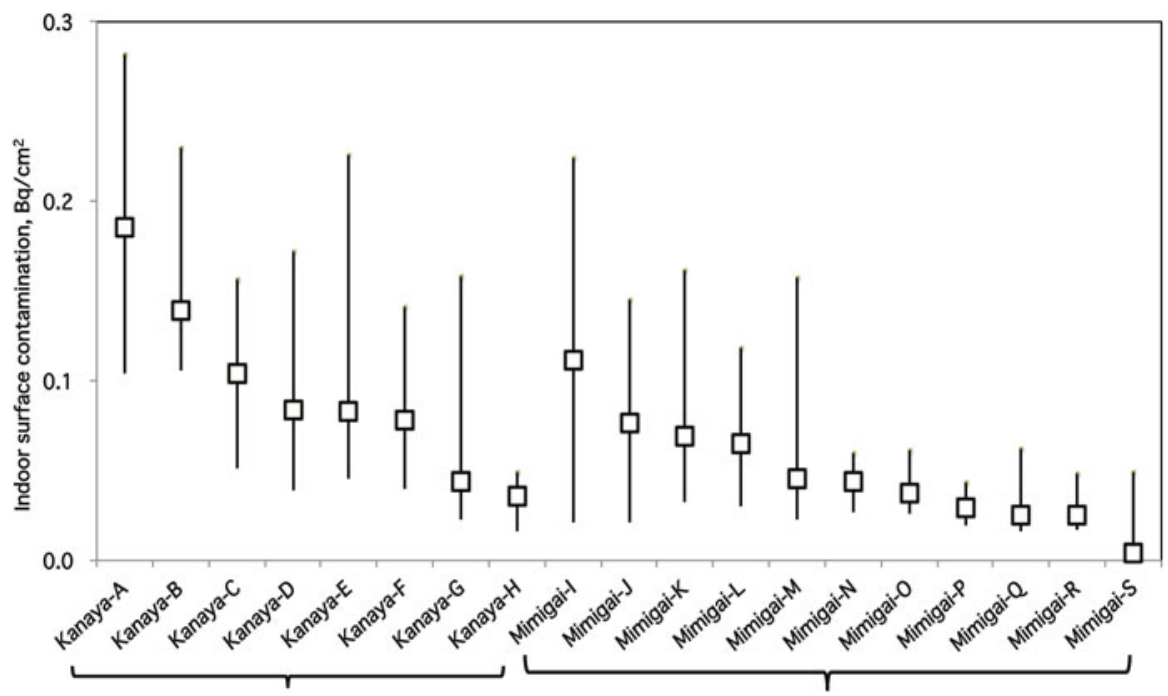

Fig. 13.3 Values of surface contamination in two groups of Kanaya and Mimigai. The value of median surface contamination with an interquartile range for each house in Kanaya and that in Mimigai is exhibited in the left group and the right group, respectively. The median and the interquartile range Q1-Q3 are expressed as squares and the bar, respectively

of Kanaya-B and Mimigai-S showing the minimum value of surface contamination in each group, could use running water and they quite often returned home after the restricted area was rearranged on April 2012. Even if the smear samples were carefully collected from places that were not cleaned or wiped, the frequency of residents' entering the house could have an effect on the level of surface contamination.

For houses in Kanaya and Mimigai, the ambient dose equivalents [ $\left.H^{*}(10)\right]$ were measured outdoors using a $1^{\prime \prime} \varphi \times 1^{\prime \prime} \mathrm{NaI}(\mathrm{Tl})$ scintillation survey meter TCS172B (Hitachi Aloka Medical, Ltd. Japan). $H^{*}(10)$ was measured outdoors at three or four points for each house and at a height of $1 \mathrm{~m}$ above the ground. At each point, measurements were collected by changing the direction of the probe of the survey meter to the four directions of east, west, north, and south, and each measurement was repeated three times. The measurement was conducted before the decontamination work started and all values were corrected to those in November 2013. An average $\pm \sigma$ was obtained for each house, as shown in Fig. 13.4, in the same order as the order of the data in Fig. 13.3. There is a clear discrepancy in the ambient dose equivalents between two groups of Kanaya and Mimigai, showing considerably lower values in the Mimigai group than those in the Kanaya group. A large discrepancy in the values of surface contamination for each house observed, seen in Fig. 13.3, is not seen in Fig. 13.4. It should be noted that Mimigai-I had a relatively low ambient dose equivalent, although the indoor surface contamination was relatively high. 


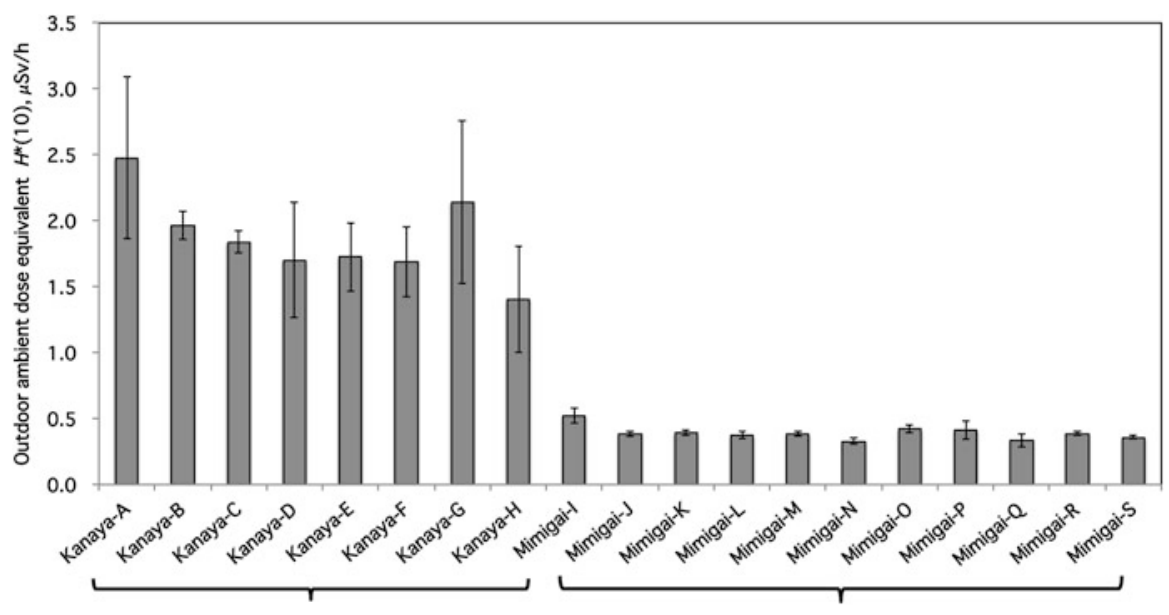

Fig. 13.4 Outdoor ambient dose equivalents $\left[H^{*}(10)\right]$ for houses in Kanaya and Mimigai. An average $\pm \sigma$ for each house is shown in Fig. 13.4 in the same order as the order of the data in Fig. 13.3. The average and 1 standard deviation are expressed as columns and the bar, respectively

\subsubsection{Effect of Surface Contamination on the Indoor Ambient Dose Equivalent}

The effect of surface contamination on the indoor ambient dose equivalent was evaluated. The photon flux, $\varphi$ (photons $/ \mathrm{sec} / \mathrm{cm}^{2}$ ) at a point $h \mathrm{~m}$ distant from the center of a disk-shaped isotropic source with a radius of $R \mathrm{~m}$, homogeneously emitting, is obtained by the following equation [8]:

$$
\varphi=\frac{Q_{s}}{4} \ln \frac{R^{2}+h^{2}}{h^{2}}
$$

By applying $1 \mathrm{~cm}$ dose equivalent rate constant, $\Gamma\left(\mu \mathrm{Sv} \cdot \mathrm{m}^{2} / \mathrm{MBq} / \mathrm{h}\right)$ to $\mathrm{Eq}$. (13.3), the ambient dose equivalent rate, $H(\mu \mathrm{Sv} / \mathrm{h})$ at a point $h \mathrm{~m}$ distant from the center of a disk-shaped isotropic source with a radius of $R \mathrm{~m}$ is obtained by Eq. (13.4), assuming radioactivity of $1.0 \mathrm{~Bq} / \mathrm{cm}^{2}$ is homogeneously distributed in the source,

$$
H=\frac{\pi}{10^{2}} \Gamma \ln \frac{R^{2}+h^{2}}{h^{2}}
$$

Assuming two horizontal phases of the house with dimensions $10 \times 10 \times 3 \mathrm{~m}$ are homogeneously contaminated with the maximum median radioactivity observed in Kamiura $\left(0.1 \mathrm{~Bq} / \mathrm{cm}^{2}\right)$ for 27 houses investigated, the ambient dose equivalent rate for ${ }^{134} \mathrm{Cs}$ and ${ }^{137} \mathrm{Cs}$ in November 2013 was calculated to be approximately $0.002 \mu \mathrm{Sv} / \mathrm{h}$. 
The loose and removable surface contamination would cause not only external exposure but also internal exposure from intakes by ingestion and/or inhalation of radioisotopes. We evaluated an example of committed effective dose ( $\mu \mathrm{Sv}$ ) using the radioactivity in dirt in a bag, which was sucked by a vacuum cleaner in the house (Kanaya-E) from the date before the earthquake occurred to November 2013 and effective dose coefficient given by ICRP 72 [9]. The radionuclide concentrations were counted using a high-purity germanium (HPGe) detector ORTEC-GMX-20195-S for $1000 \mathrm{~s}$, revealing that concentrations for ${ }^{134} \mathrm{Cs}$ and ${ }^{137} \mathrm{Cs}$ were $68,600 \pm 0$ and $170,400 \pm 0 \mathrm{~Bq} / \mathrm{kg}$ (corrected to November 2013), respectively. In a case that an adult (more than 17 years) once intakes $0.1 \mathrm{~g}$ of dust by ingestion, the committed effective dose was calculated to be $0.35 \mu \mathrm{Sv}$ as ingestion dose coefficients are 0.019 and $0.013 \mu \mathrm{Sv} / \mathrm{Bq}$ [9] for ${ }^{134} \mathrm{Cs}$ and ${ }^{137} \mathrm{Cs}$, respectively.

Both, dose of external and internal exposure due to indoor deposition of radiocaesium are evaluated to be relatively low. Surface contamination is loose and easily removable. In our trials of cleaning, surface contamination for wooden materials was reduced to one-tenth after wiping with chemical wiping cloths and further reduced to below the detection limit after wiping with a damp cloth. From a viewpoint of radiation protection, it is strongly recommended to remove surface contamination by cleaning the house before residents return home.

\subsection{Conclusion}

The indoor deposition of radiocaesium was investigated for 27 wooden houses in eight areas in Odaka district using dry smear test. Comparison of surface contamination between Kanaya and Mimigai houses revealed that the values of surface contamination in Kanaya tended to be were larger than those in Mimigai; however, a large discrepancy for each individual house was observed in both groups. The frequency of residents' entering their house might have an effect on the level of surface contamination. We evaluated external and internal exposure dose due to indoor deposition of radiocaesium and found that these values are relatively low. Surface contamination is loose and easily removable. In our trials, surface contamination for wooden materials was reduced to below the detection limit after wiping with chemical wiping cloths and a damp cloth. From a viewpoint of radiation protection, it is strongly recommended to remove surface contamination by cleaning the house before the residents return home.

Acknowledgments This work was partly supported by a study of the Health Effects of Radiation organized by the Ministry of Environment, Japan. The authors thank Mr. Takemi Nemoto (Odaka ward office) for his help in recruiting house owners for investigation and Ms. Eri Hayasaka for her assistance in this study. 
Open Access This chapter is distributed under the terms of the Creative Commons Attribution Noncommercial License, which permits any noncommercial use, distribution, and reproduction in any medium, provided the original author(s) and source are credited.

\section{References}

1. Nuclear Emergency Response Headquarters of Government of Japan (2011) Report of the Japanese Government to the IAEA ministerial conference on nuclear safety-the accident at TEPCO's Fukushima nuclear power stations. http://japan.kantei.go.jp/kan/topics/201106/iaea_ houkokusho_e.html. Accessed 7 May 2015

2. Nuclear Emergency Response Headquarters of Government of Japan (2011) Additional report of the Japanese Government to the IAEA - the accident at TEPCO's Fukushima nuclear power stations-(Second report). https://www.iaea.org/sites/default/ files/japanreport120911.pdf\#search=|T1\textquoteleftNuclear+Emergency+Response+ Headquarters+of+Government+of+Japan\%2C+Additional+Report+of+the+Japanese+ Government+to+the+IAEAIT1 \textemdashThe+Accident+at+TEPCOIT1\textquoterights+ Fukushima+Nuclear+Power+Stations\T1 \textemdash\%28Second+Report\%29. Accessed May 2015

3. Yoshida-Ohuchi $\mathrm{H}$ et al (2013) Evaluation of personal dose equivalent using optically stimulated luminescent dosemeters in Marumori after the Fukushima Nuclear Accident. Rad Protec Dosim 154:385. doi: $10.1093 / \mathrm{rpd} / \mathrm{ncs} 245$

4. Minister of Economy (2013) Trade and industry, evacuation areas, areas to which evacuation orders have been issued. http://www.meti.go.jp/english/earthquake/nuclear/roadmap/pdf/ 20130807_01.pdf. Accessed 7 May 2015

5. JIS Z 4504 (2008) Evaluation of surface contamination beta-emitters (maximum beta energy greater than $0.15 \mathrm{MeV}$ ) and alpha-emitters (in Japanese). http://kikakurui.com/z4/Z4504-200801.html. Accessed 7 May 2015

6. Frame PW, Abelquist EW (1999) Use of smears for assessing removable contamination. Health Phys 76(Supplement 2):S57-S66

7. Cooper JA (1970) Factors determining the ultimate detection sensitivity of Ge(Li) gamma-ray spectrometers. Nucl Instr Methods 82:273-277

8. Nakamura $T$ (2001) Radiation physics and accelerator safety engineering, 2nd edn. Chijinshokan, Tokyo (in Japanese)

9. ICRP (1995) Publication 72: Age-dependent doses to the members of the public from intake of radionuclides part 5, compilation of ingestion and inhalation coefficients: annals of the ICRP volume 26/1, 1e (International Commission on Radiological Protection) 